\title{
Simple Solution-Phase Syntheses of Tetrahalodiboranes(4) and their Labile Dimethylsulfide Adducts
}

Merle Arrowsmith, ${ }^{1,2}$ Julian Böhnke, ${ }^{1,2}$ Holger Braunschweig, ${ }^{1,2} *$ Andrea Deißenberger, ${ }^{1,2}$ Rian D. Dewhurst, ${ }^{1,2}$ William C. Ewing, ${ }^{2,3}$ Christian Hörl, ${ }^{1}$ Jan Mies, ${ }^{1}$ Jonas H. Muessig ${ }^{1,2}$

Convenient, solution-phase syntheses of tetrahalodiboranes(4) $\mathrm{B}_{2} \mathrm{~F}_{4}, \mathrm{~B}_{2} \mathrm{Cl}_{4}$ and $\mathrm{B}_{2} \mathrm{I}_{4}$ are presented herein from common precursor $\mathrm{B}_{2} \mathrm{Br}_{4}$. In addition, the dimethylsulfide adducts $\mathrm{B}_{2} \mathrm{Cl}_{4}\left(\mathrm{SMe}_{2}\right)_{2}$ and $\mathrm{B}_{2} \mathrm{Br}_{4}\left(\mathrm{SMe}_{2}\right)_{2}$ are conveniently prepared in one-step syntheses from the commercially-available starting material $\mathrm{B}_{2}\left(\mathrm{NMe}_{2}\right)_{4}$. The results provide simple access to the full range of tetrahalodiboranes(4) for the exploration of their untapped synthetic potential.

Diboranes(4), compounds of the form $\mathrm{B}_{2} \mathrm{X}_{4}$, are of immense interest for organic synthesis, given their position as reagents of choice for installing boron functional groups into organic molecules for further synthetic transformations. ${ }^{1}$ Consequently, attention paid to the reactivity of diboranes(4) is focused overwhelmingly on the B-B bond, and the use of diboranes(4) with reactive $B-X$ bonds is negligible in comparison. ${ }^{1 \mathrm{c}}$

Tetrahalodiboranes(4) $\left(\mathrm{B}_{2} \mathrm{X}_{4} ; \mathrm{X}=\right.$ halide) have been known since Stock's 1925 synthesis of $\mathrm{B}_{2} \mathrm{Cl}_{4}$ by reduction of $\mathrm{BCl}_{3}$ with a zinc arc discharge. $^{2}$ With their highly reactive $B-X$ bonds, tetrahalodiboranes(4) represent intriguing alternatives to the diboranes in frequent use in organic synthesis (e.g. dicatechol- and dipinacoldiborane(4)). However, tetrahalodiboranes(4) are littleused in contemporary main-group chemistry and their synthetic possibilities have only been cursorily explored. The gas-phase synthesis of a number of tetrahalodiboranes, $B_{2} X_{4}(X=\text { halide })^{3}$ in the mid-20th century saw a flurry of research activity into their properties and reactivity. This peaked in the early 1960s, impelled in part by the discovery that tetrahalodiboranes(4) could be used as reagents for the diboration of olefins and aromatic organic compounds (A, Figure 1). ${ }^{4}$ The groups of Nöth $^{5}$ and Haubold ${ }^{6}$ reported relatively convenient solution-phase syntheses of $\mathrm{B}_{2} \mathrm{Br}_{4}$ and $B_{2} I_{4}$, respectively, in the 1980s, and around the same time a range of unusual alkyne diboration reactions with $\mathrm{B}_{2} \mathrm{Cl}_{4}$ were reported by Siebert. ${ }^{7}$ However, the research interest in tetrahalodiboranes(4) never again reached the early heights attained in the 1960 s.

Given the obvious synthetic value of tetrahalodiboranes(4) in a number of fields, and the high interest in these compounds in the 1950 s and 1960s, the current non-commercial use of these reagents remains remarkably low, with fewer than five publications per year. In fact, over the past five years, the filing of patents involving tetrahalodiboranes(4) has outpaced their appearance in journal articles at a rate of two to one. ${ }^{8}$ In particular, $\mathrm{B}_{2} \mathrm{~F}_{4}$ has attracted intense industrial interest over the past few years as a reagent for implantation of $\mathrm{B}^{+}$ions into silicon for semiconductor device fabrication. $B_{2} F_{4}$ offers more facile ionization and fragmentation than $\mathrm{BF}_{3}$, the current primary feed gas for this application, while also being compatible with conventional ion implant platforms. ${ }^{9}$
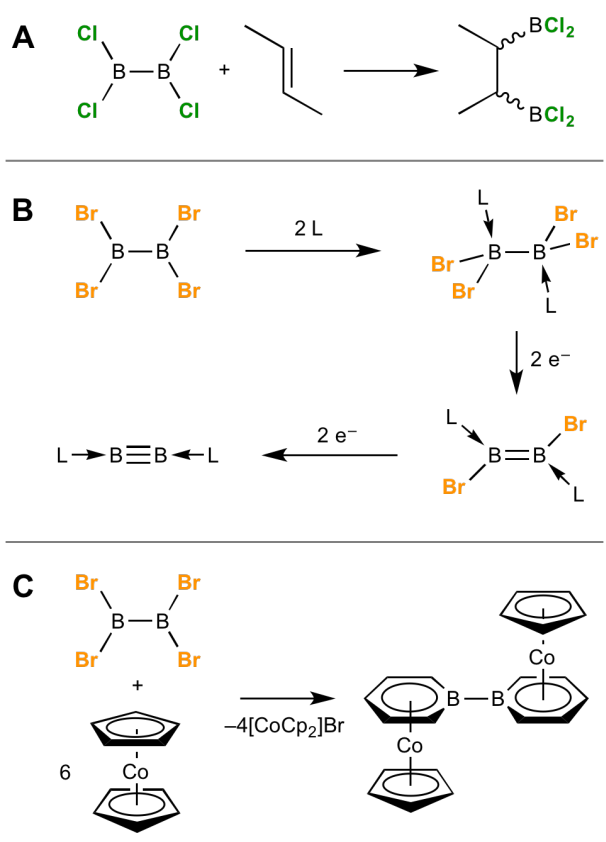

Figure 1 Selected synthetic uses of tetrahalodiboranes(4).

In recent years, interest in the condensed-phase reactivity of tetrahalodiboranes(4) has come almost exclusively from our laboratories, where $\mathrm{B}_{2} \mathrm{Br}_{4}$ is used as a precursor for Lewis base adducts and the construction of boron-boron multiple bonds ( $B$, Figure 1), ${ }^{1 \mathrm{a}, \mathrm{b}, \mathrm{f}, 10}$ as well as precursors to bis(boratabenzene) ligands in transition metal complexes (C, Figure 1). ${ }^{11}$ Beyond these applications, however, tetrahalodiboranes(4) offer a near-unlimited number of intriguing possibilities in organic, main-group, transitionmetal, and materials chemistry that we have only begun to explore.

The hesitance of the scientific community to adopt these versatile reagents clearly stems from their synthetic routes, which are tedious, temperamental, and require special apparatus in some cases. Given these hurdles, we set out to develop simple, solutionphase syntheses of all four tetrahalodiboranes $(4)\left(B_{2} X_{4} ; X=F(1 a), C l\right.$ (1b), $B r(\mathbf{1 c}), \quad$ ( (1d)), in order to open up these reagents for widespread use. These reactions are presented herein, in addition to facile synthetic routes to tetrahalodiborane bis(dimethylsulfide) adducts $\left(\mathrm{B}_{2} \mathrm{X}_{4}\left(\mathrm{SMe}_{2}\right)_{2} ; \mathrm{X}=\mathrm{Cl}(\mathbf{2} \mathbf{b}), \mathrm{Br}(\mathbf{2 c}), \mathrm{I}(\mathbf{2 d})\right)$, two of which in a single step from commercially available precursor $B_{2}\left(\mathrm{NMe}_{2}\right)_{4}$. These adducts are more conveniently handled compounds that in many cases can play the same synthetic role as their tetrahalodiborane(4) analogues.

In our laboratories, Nöth's 1981 synthesis of $\mathrm{B}_{2} \mathrm{Br}_{4}(\mathbf{1 c})^{5}$ from $\mathrm{B}_{2}(\mathrm{OMe})_{4}$ using tribromoborane (Figure 2) still provides the most convenient entry to tetrahalodiboranes(4), and reliable solutionphase routes exist to $\mathrm{B}_{2} \mathrm{~F}_{4}(\mathbf{1 a})$ and $\mathrm{B}_{2} \mathrm{I}_{4}(\mathbf{1 d})$ from $\mathrm{B}_{2} \mathrm{Cl}_{4}$ (1b) from 
Schlesinger ${ }^{3 \mathrm{~d}}$ and Haubold, ${ }^{6}$ respectively. Although Timms was able to prepare $\mathrm{B}_{2} \mathrm{Cl}_{4}$ on a ca. $10 \mathrm{~g}$ scale by metal vapour deposition of molten copper with trichloroborane, ${ }^{12}$ we are aware of no convenient solution-phase route to the compound, making the synthesis of $\mathrm{B}_{2} \mathrm{~F}_{4}$ and $\mathrm{B}_{2} \mathrm{I}_{4}$ difficult by extension. We reasoned that with judicious choice of reagents, we may be able to connect $\mathrm{B}_{2} \mathrm{Br}_{4}$ with the remaining tetrahalodiboranes $\mathbf{1 a}, \mathbf{b}, \mathbf{d}$.

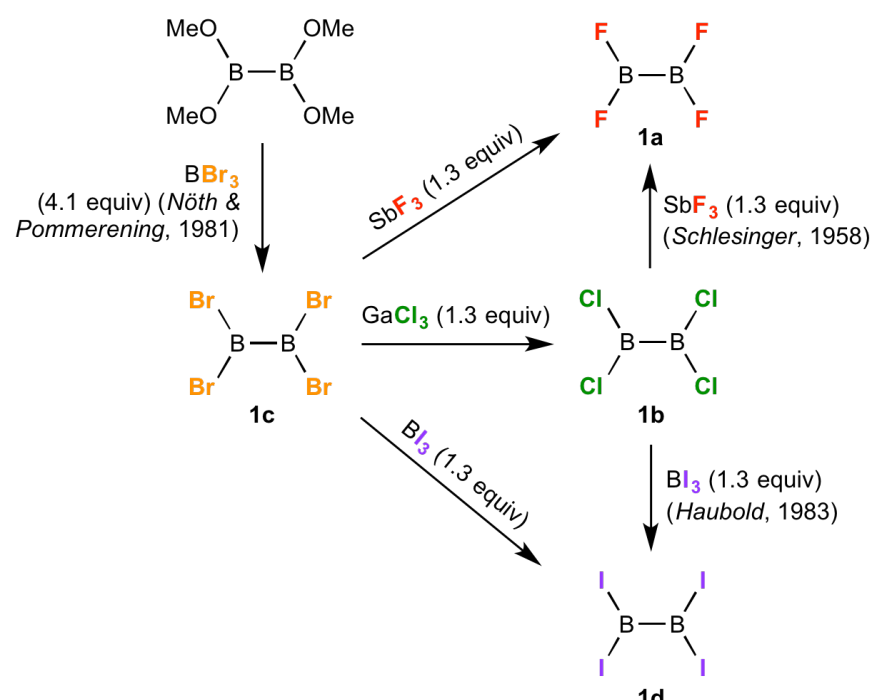

Figure 2 Old and new syntheses of tetrahalodiboranes(4).

Treatment of $\mathrm{B}_{2} \mathrm{Br}_{4}$ with 1.3 equiv of either trifluorostibane, trichlorogallane, or triiodoborane, led to solutions of $\mathrm{B}_{2} \mathrm{~F}_{4}, \mathrm{~B}_{2} \mathrm{Cl}_{4}$ or $\mathrm{B}_{2} \mathrm{I}_{4}$, respectively. The lighter tetrahalodiboranes(4) $\mathrm{B}_{2} \mathrm{~F}_{4}$ and $\mathrm{B}_{2} \mathrm{Cl}_{4}$ could be vacuum distilled from the heavy $\mathrm{Sb} / \mathrm{Ga}$ salts, providing hexane solutions that can be used for further reactions by assuming complete conversion. In contrast, $\mathrm{B}_{2} \mathrm{l}_{4}$ was isolated as a colourless solid by vacuum distillation of the lighter byproducts out of the reaction mixture. The ${ }^{11} \mathrm{~B}$ NMR spectra of the tetrahalodiboranes(4) match the reported data, ${ }^{6}$ with a relatively high-field signal being observed for $\mathrm{B}_{2} \mathrm{~F}_{4}\left(\delta_{\mathrm{B}} 22.1\right)$, and low-field signals for $\mathrm{B}_{2} \mathrm{Cl}_{4}\left(\delta_{\mathrm{B}} 61.9\right)$ and $\mathrm{B}_{2} \mathrm{I}_{4}\left(\delta_{\mathrm{B}} 70\right)$. A single resonance at $\delta_{\mathrm{F}}-130$ was also found in the ${ }^{19} \mathrm{~F}$ NMR spectrum of $\mathrm{B}_{2} \mathrm{~F}_{4}$.

While these synthetic routes improve markedly upon the previous routes, and offer practical solution-phase conditions, the syntheses of 1a-c still comprise three- or four-step protocols from the commercially-available precursor $\mathrm{B}_{2}\left(\mathrm{NMe}_{2}\right)_{4}$. This prompted us to seek a more direct route to the target compounds 1 a-d. In general, treatment of $\mathrm{B}_{2}\left(\mathrm{NMe}_{2}\right)_{4}$ with trihalotriels fails to produce 1a-d. However, we found that combining $\mathrm{B}_{2}\left(\mathrm{NMe}_{2}\right)_{4}$ with excesses of the dimethylsulfide monoborane adducts $\mathrm{BX}_{3}\left(\mathrm{SMe}_{2}\right)(\mathrm{X}=\mathrm{Cl}, \mathrm{Br})$ led to complete conversion to the bis-adducts $\mathrm{B}_{2} \mathrm{X}_{4}\left(\mathrm{SMe}_{2}\right)_{2}$ (2b: $\mathrm{X}=$ $\mathrm{Cl} ; \mathbf{2 c}$ : $\mathrm{X}=\mathrm{Br}$; Figure 3 ), which could be isolated as colourless solids in good yields by removal of monoborane byproducts $\left(\left[\mathrm{BCl}_{2}\left(\mathrm{NMe}_{2}\right)\right]_{2}\right.$ and $\mathrm{BBr}_{n}\left(\mathrm{NMe}_{2}\right)_{3-\mathrm{n}}(\mathrm{n}=1,2)$, respectively) by fractional crystallisation and vacuum distillation. The bis-adducts $\mathbf{2} \mathbf{b}$ and $\mathbf{2 c}$ were identified by their sharp, high-field signals ( $2 \mathrm{~b}: \delta_{\mathrm{B}} \mathbf{7 . 3}$; 2c: $\delta_{\mathrm{B}}-0.3$ ), in addition to single-crystal $\mathrm{X}$-ray diffractometry (vide infra, Figure 4) and elemental analysis. It should also be noted that $\mathbf{2 b}$ can also be prepared by addition of 2 equiv of $\mathrm{BCl}_{3}\left(\mathrm{SMe}_{2}\right)$ to $\mathrm{B}_{2} \mathrm{Cl}_{2}\left(\mathrm{NMe}_{2}\right)_{2}$, or alternatively by simple addition of an excess of dimethylsulfide to $\mathrm{B}_{2} \mathrm{Cl}_{4}$ (Figure 3). Likewise, $2 \mathrm{c}$ can be prepared by addition of excess dimethylsulfide to $\mathrm{B}_{2} \mathrm{Br}_{4}$.
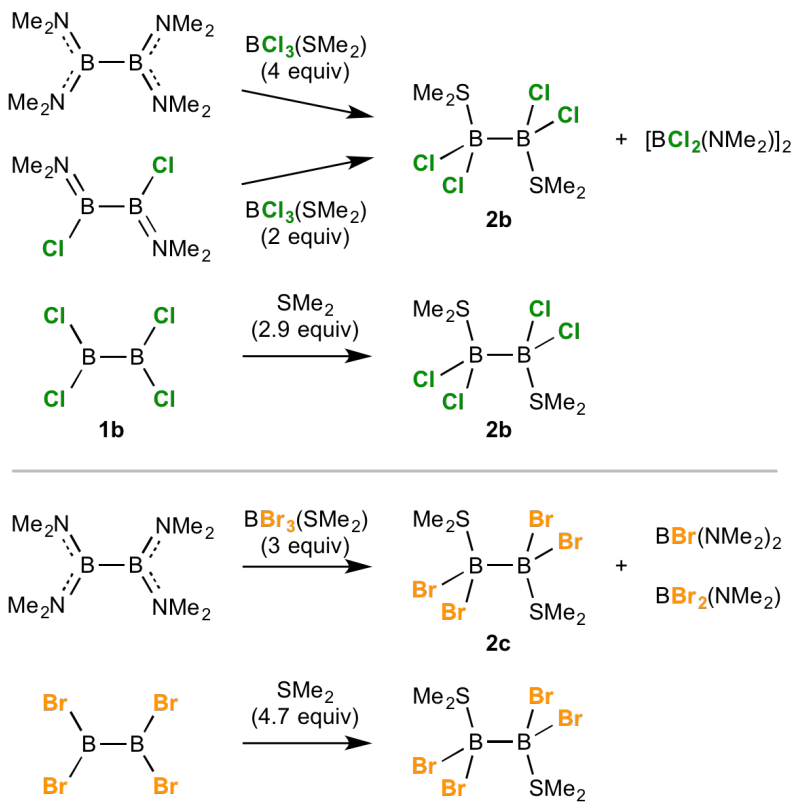<smiles>IB(I)B(I)I</smiles>

1d

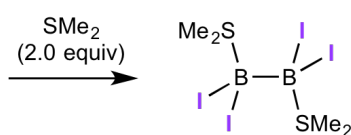

2d
Figure 3 Syntheses of dimethylsulfide adducts of tetrahalodiboranes(4).

Unfortunately, all attempts to prepare the iodo analogue $\mathrm{B}_{2} \mathrm{I}_{4}\left(\mathrm{SMe}_{2}\right)_{2}(\mathbf{2 d}: \mathrm{X}=\mathrm{I}$; Figure 3 ) by a similarly direct route were unsuccessful. However, the tetraiodo derivative was found to be accessible by addition of dimethylsulfide to $\mathrm{B}_{2} \mathrm{I}_{4}$, providing $\mathbf{2 d}$ as colourless crystals in excellent yield. This compound showed an ${ }^{11} \mathrm{~B}$ NMR signal $\left(\delta_{B}-20\right)$ even further upfield of those of $\mathbf{2} \mathbf{b}$ and $\mathbf{2 c}$.

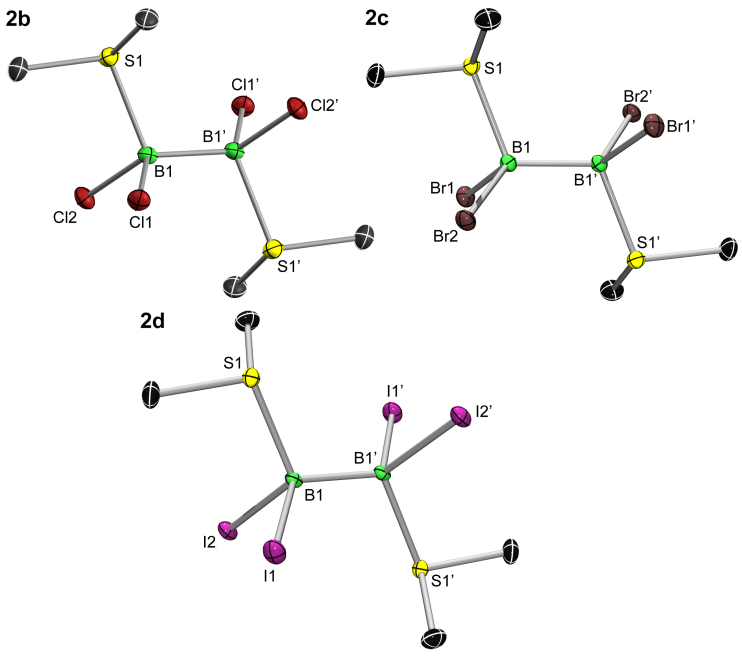

Figure 4 Crystallographically-derived structures of $\mathbf{2 b}$-d. Thermal ellipsoids set at the $50 \%$ probability level. Hydrogen atoms have been removed for clarity. Selected bond lengths $[\AA]$ and angles $\left[{ }^{\circ}\right]$ for 2 b: B-B $1.719(2), B-S$ $1.976(1), B-C l$ 1.861(1), 1.868(1). For 2c: B-B 1.715(4), B-S 1.961(2), B-Br 2.026(2), 2.051(2). For 2d: B-B 1.714(7), B-S 1.955(4), B-I 2.250(3), 2.280(3). 
The crystallographically-derived structures of $\mathbf{2 b - \mathbf { d }}$ (Figure 4) show equivalent $B-B$ bond lengths within experimental error (2b: 1.719(2); 2c: 1.715(4); 2d: 1.714(7) Å), despite steadily increasing B$X$ distances (2b: B-Cl 1.861(1), 1.868(1); 2c: B-Br 2.026(2), 2.051(2); 2d: $B-I$ 2.250(3), 2.280(3) $\AA$ ) as the halides become larger. $A$ moderate contraction of the B-S bonds is observed along this series (2b: B-S 1.976(1); 2c: B-S 1.961(2); 2d: B-S 1.955(4) Å), presumably due to lengthening $B-X$ bonds and increasing Lewis acidity of the attached boron atoms.

The results presented herein provide convenient solution-phase access to all four tetrahalodiboranes, as well as one-step syntheses of $\mathrm{B}_{2} \mathrm{Cl}_{4}\left(\mathrm{SMe}_{2}\right)_{2}$ and $\mathrm{B}_{2} \mathrm{Br}_{4}\left(\mathrm{SMe}_{2}\right)_{2}$ from the commercially-available precursor $\mathrm{B}_{2}\left(\mathrm{NMe}_{2}\right)_{4}$. We present these protocols in the hope that these reagents can find widespread use throughout the community, and their promising synthetic potential can be fully realised. We wish readers the best of luck in their synthetic endeavours.

This project was funded by the European Research Council (ERC) under the European Union Horizon 2020 Research and Innovation Program (grant agreement no. 669054, to H.B.), and the Alexander von Humboldt foundation (postdoctoral research fellowship to M.A.).

\section{Notes and references}

1 Selected reviews on diboranes and their synthetic uses: (a) M. Arrowsmith, H. Braunschweig, T. E. Stennett, Angew. Chem. Int Ed., 2017, 56, 96-115; (b) E. C. Neeve, S. J. Geier, I. A. I. Mkhalid, S. A. Westcott, T. B. Marder, Chem. Rev., 2016, 116, 9091-9161; (c) R. D. Dewhurst, E. C. Neeve, H. Braunschweig, T. B. Marder, Chem. Commun., 2015, 51, 9594-9607; (d) H. Braunschweig, R. D. Dewhurst, S. Mozo, Chem. Cat. Chem., 2015, 7, 1630-1638; (e) S. A. Westcott, E. Fernández, Adv. Organomet. Chem., 2015, 63, 3989; (f) H. Braunschweig, R. D. Dewhurst, Angew. Chem. Int. Ed., 2013, 52, 3574-3583; (g) J. Takaya, N. Iwasawa, ACS Catal., 2012, 2, 1993-2006; (h) I. A. I. Mkhalid, J. H. Barnard, T. B. Marder, J. M. Murphy, J. F. Hartwig, Chem. Rev., 2010, 110, 890-931; (i) H. E. Burks, J. P. Morken, Chem. Commun., 2007, 4717-4725; (j) T. B. Marder, N. C. Norman, Top. Catal., 1998, 5, 63-73.

2 A. Stock, A. Brandt, H. Fischer, Chem. Ber., 1925, 58, 643-657.

3 (a) T. Wartik, R. Moore, H. I. Schlesinger, J. Am. Chem. Soc., 1949, 71, 3265-3266; (b) G. Urry, T. Wartik, R. E. Moore, H. I. Schlesinger, J. Am. Chem. Soc., 1954, 76, 5293-5298. (c) G. Urry, J. Kerrigan, T. D. Parsons and H. I. Schlesinger, J. Am. Chem. Soc., 1954, 76, 52995301; (d) A. Finch and H. I. Schlesinger, J. Am. Chem. Soc., 1958, 80, 3573-3574. (e) P. Ceron, A. Finch, J. Frey, J. Kerrigan, T. Parsons, G. Urry, H. I. Schlesinger, J. Am. Chem. Soc., 1959, 81, 6368-6371.

4 (a) J. Feeney, A. K. Holliday, F. J. Marsden, J. Chem. Soc., 1961, 356-360; (b) W. B. Fox, T. Wartik, J. Am. Chem. Soc., 1961, 83, 498499; (c) C. Pubill-Ulldemolins, E. Fernánez, C. Bo, J. M. Brown, Org. Biomol. Chem., 2015, 13, 9619-9628.

5 H. Nöth, H. Pommerening, Chem. Ber., 1981, 114, 398-399.

6 W. Haubold, P. Jacob, Z. anorg. allg. Chem., 1983, 507, 231-234.

7 (a) M. Hildenbrand, H. Pritzkow, U. Zenneck, W. Siebert, Angew. Chem., 1984, 96, 371-372; (b) P. Hornbach, M. Hildenbrand, H. Pritzkow, W. Siebert, Angew. Chem., 1986, 98, 1121-1123.

8 Over the period 2012-2017, 27 patents were filed and 13 journal articles published concerning tetrahalodiboranes(4).

9 (a) O. Byl, E. Jones, J. Sweeney and R. Kaim, AIP Conf. Proc., 2011, 1321, 408-410; (b) Y. Tang, O. Byl, A. Avila, J. Sweeney, R. Ray, J. Koo, M.-S. Jeon, T. Miller, S. Krause, W. Skinner, J. Mullin, 20th International Conference on Ion Implantation Technology (IIT), 2014. DOI: 10.1109/IIT.2014.6939984.

10 (a) H. Braunschweig, R. D. Dewhurst, K. Hammond, J. Mies, K. Radacki, A. Vargas, Science, 2012, 336, 1420-1422; (b) J. Böhnke,
H. Braunschweig, W. C. Ewing, C. Hörl, T. Kramer, I. Kummenacher, J. Mies, A. Vargas, Angew. Chem. Int. Ed., 2014, 53, 9082-9085; (c) J. Böhnke, H. Braunschweig, P. Constantinidis, T. Dellermann, W. C. Ewing, I. Fischer, K. Hammond, F. Hupp, J. Mies, H.-C. Schmitt, A. Vargas, J. Am. Chem. Soc., 2015, 137, 1766-1769; (d) J. Böhnke, H. Braunschweig, T. Dellermann, W. C. Ewing, K. Hammond, T. Kramer, J. O. C. Jimenez-Halla, J. Mies, Angew. Chem. Int. Ed., 2015, 54, 13801-13805; (e) J. Böhnke, H. Braunschweig, T. Dellermann, W. C. Ewing, T. Kramer, I. Krummenacher, A. Vargas, Angew. Chem. Int. Ed., 2015, 54, 4469-4473; (f) M. Arrowsmith, J. Böhnke, H. Braunschweig, M. A. Celik, T. Dellermann, K. Hammond, Chem. Eur. J., 2016, 22, 17169-17172.

11 H. Braunschweig, S. Demeshko, W. C. Ewing, I. Krummenacher, B. B. Macha, J. D. Mattock, F. Meyer, J. Mies, M. Schäfer, A. Vargas, Angew. Chem. Int. Ed., 2016, 55, 7708-7711.

12 (a) P. L. Timms, J. Chem. Soc., Dalton Trans., 1972, 830-832; (b) P. L. Timms, Inorg. Synth., 1979, 19, 74-78. 


\section{TOC Entry:}

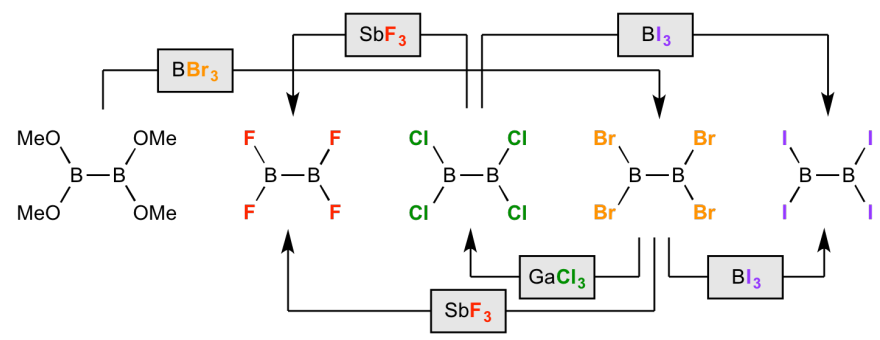

